\title{
Stereospecific Cross-Coupling of Secondary Alkyl Trifluoroborates
}

\section{Key words}

cross-coupling

C-C coupling

stereospecificity

organotrifluoro-

borates

palladium

CPME = cyclopentyl methyl ether
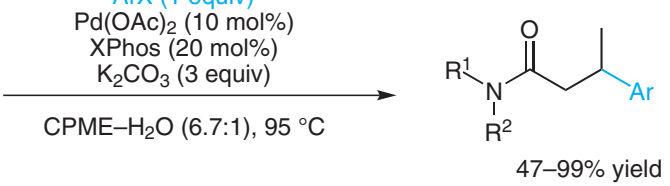

SYNFACTrath
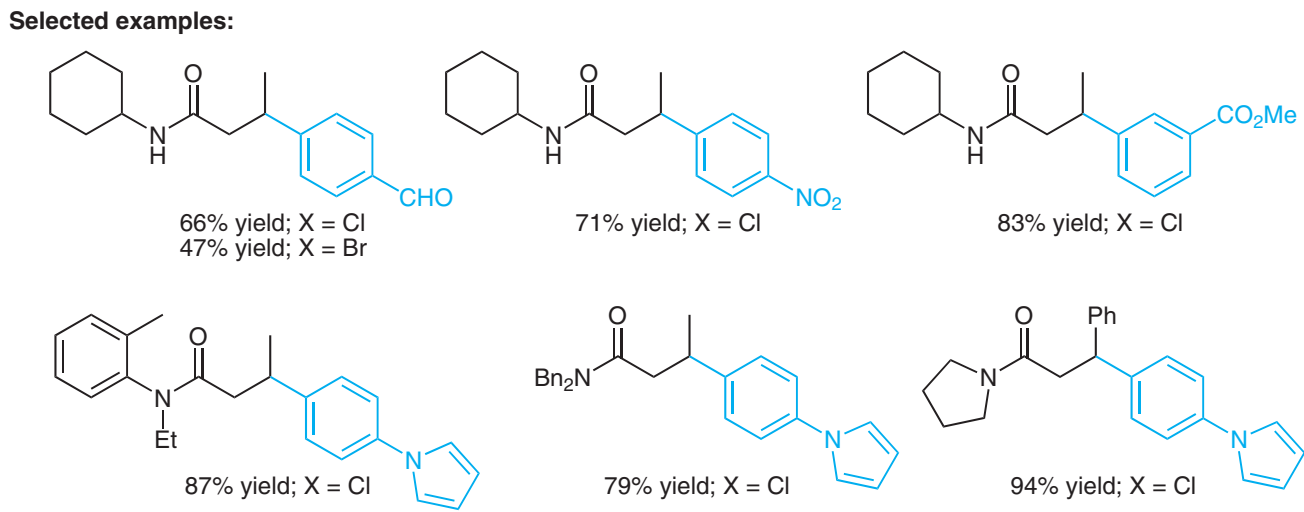

$83 \%$ yield $\mathrm{X}=\mathrm{Cl}$
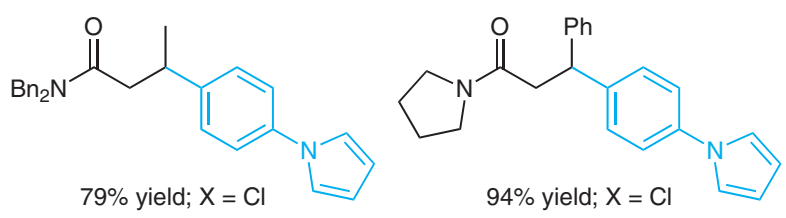

Stereochemistry:<smiles>COc1ccc(NC(=O)CC(C)C(F)(F)Br)cc1</smiles>

$(S) /(R)=7: 93$

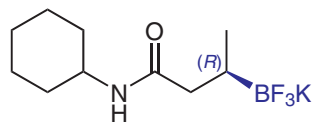

$(S) /(R)=6: 94$

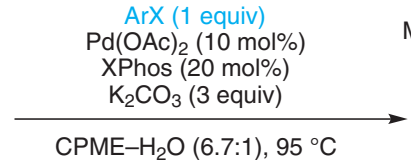

CPME- $\mathrm{H}_{2} \mathrm{O}(6.7: 1), 95{ }^{\circ} \mathrm{C}$

ArX (1 equiv) $\mathrm{Pd}(\mathrm{OAc})_{2}(10 \mathrm{~mol} \%)$ XPhos (20 mol\%) $\mathrm{K}_{2} \mathrm{CO}_{3}$ (3 equiv)

CPME- $\mathrm{H}_{2} \mathrm{O}(6.7: 1), 95^{\circ} \mathrm{C}$<smiles>CCCC(=O)Nc1ccc(OC)cc1</smiles>

$82 \%$ yield $(S) /(R)=95: 5$

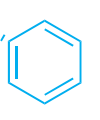

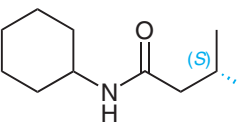

$91 \%$ yield $(S) /(R)=92: 8$

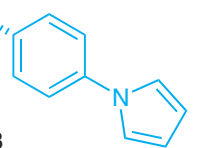

Significance: The cross-coupling of $\beta$-trifluoroboratoamides was shown to proceed with high selectivity. Thereby, the carbonyl group of the amide moiety serves as a hemilabile ligand inhibiting the undesired $\beta$ - $\mathrm{H}$-elimination pathway.
Comment: This remarkable cross-coupling of enantioenriched nonbenzylic secondary alkyl boron compounds with aryl halides was shown to proceed stereospecifically with inversion of configuration. This stereochemical outcome is attributed to an intramolecular coordination of the carbonyl group to the boron.

SYNFACTS Contributors: Paul Knochel, Tobias Thaler

DoI: 10.1055/s-0030-1259233; Reg-No.: P16810SF 